\title{
Multistage Warning Indicators of Concrete Dam under Influences of Random Factors
}

\author{
Guang Yang ${ }^{1,2}$ and Meng Yang ${ }^{1,3}$ \\ ${ }^{1}$ State Key Laboratory of Hydrology-Water Resources and Hydraulic Engineering, Hohai University, Nanjing 210098, China \\ ${ }^{2}$ National Engineering Research Center of Water Resources Efficient Utilization and Engineering Safety, Hohai University, \\ Nanjing 210098, China \\ ${ }^{3}$ College of Water-Conservancy and Hydropower, Hohai University, Nanjing 210098, China
}

Correspondence should be addressed to Meng Yang; ymym_059@126.com

Received 25 November 2015; Revised 25 February 2016; Accepted 21 March 2016

Academic Editor: Paolo Crippa

Copyright (C) 2016 G. Yang and M. Yang. This is an open access article distributed under the Creative Commons Attribution License, which permits unrestricted use, distribution, and reproduction in any medium, provided the original work is properly cited.

\begin{abstract}
Warning indicators are required for the real-time monitoring of the service conditions of dams to ensure safe and normal operations. Warnings are traditionally targeted at some "single point deformation" by deformation measuring points of concrete dam, and scientific warning theory on "overall deformation" measured is nonexistent. Furthermore, the influences of random factors are not considered. In this paper, the overall deformation of the dam was seen as a deformation system of single interactional observation points with different contribution degrees. The spatial deformation entropy, which describes the overall deformation, was established and the fuzziness indicator that measures the influence of complex random factors on monitoring values according to cloud theory was constructed. On this basis, multistage warning indicators of "spatial deformation" that consider fuzziness and randomness were determined. Analysis showed that the change law of information entropy of the dam' overall deformation is identical to the real change law of the dam; thus, it reflects the real deformation state of the dam. Moreover, the identified warning indicators improved the warning ability of concrete dams.
\end{abstract}

\section{Introduction}

Deformation is one of the major monitored items in dam safety. Concrete dams are exposed to influences of various nondeterministic settings such as the load effect of water level, uplift pressure, and wind waves caused by hydrologic and hydraulic uncertainties, as well as geological and material uncertainties such as shearing and compressive strength. Thus, a concrete dam is a complicated system of nondeterministic settings that are affected by various complex random factors $[1,2]$. Considering a dam's long-term service, conducting timely and effective warning against emergencies through real-time monitoring is key to its safe operation [3].

The monitoring of dam safety is an important research subject in advanced mechanics and mathematics theories. In 1950, Tonini categorized the factors influencing the displacement of dam into water pressure, temperature, and effectiveness for a given period [4]. These factors were expressed in the polynomials of specific functions before a statistic model with regression analysis was established. Then, the deterministic model and mixed model were consulted for deformation of concrete dam and introduced finite element to monitor and evaluate the safety of dams [5]. Furthermore, many scholars brought new achievements in diagnosing dam safety from many aspects. In 2009, Gu and Wang established the catastrophe model of time-dependent component on the basis of catastrophe theory and proposed the method to determine the threshold value of the structure displacement of the dam [6]. On the basis of the POT model in extreme value theory, in 2012, Su et al. estimated the warning indicators by setting the threshold value and combining the probability of dam deformation with transfinite data sequence as the subject of modeling analysis [7]. Warning indicators are sure to have some fuzziness and randomness because of the influences of various complex random factors. On the basis of the fuzzy finite element, Chen (2006) realized the nondeterministic optimal control on roller compacted concrete dam [8]. Although the above-mentioned theories 
and methods complement and improve traditional methods in solving difficult problems in dam safety, such approaches only address the warning of "point" deformation and not the scientific "spatial and overall" deformation. Further studies on the deformation of concrete dams must consider the influences of complex random factors. Thus, the expression of a dam's overall deformation should be constructed and scientific and accurate warning indicators that consider randomness and fuzziness should be determined.

This paper began with an analysis of an indicator of fuzziness that affects the value of monitoring the dam by studying the influences of fuzziness and randomness from long-term service of the dam based on cloud theory [911]. Thereafter, the relationship between a dam's overall deformation and deformation of single observation points was analyzed through information entropy and synergetics. In the analysis, overall deformation refers to a system wherein single observation points with different contribution degrees (weights) influence one another. A criterion indicator measuring the overall deformation conditions was constructed. On this basis, multistage warning indicators for the overall deformation of concrete dam considering fuzziness and randomness were determined. Therefore, nondeterministic optimal control was achieved [12]. This paper concludes with a project case that verified the feasibility of the proposed theory.

\section{Nondeterministic Optimal Control}

Hydraulic engineering considers that some fuzziness and randomness in dams are inevitable because of the influences of various random factors such as the nondeterminacy of mechanical parameters, imposed load, and boundary conditions. Statistically, the smaller probability of dam displacement indicates that the dam is in a more dangerous state. $\mu+3 \sigma$ and $\mu-3 \sigma$ can be used as a warning indicator in one confidence coefficient of the dam if the displacement obeys the normal distribution of mean value and variance and is in the range of $\mu \pm 3 \sigma$ in deterministic optimal control. In reality, given that dams are affected by random factors, warning indicators will have a range of variations. For example, in Figure 1, the warning value of upstream displacement has a maximum control value and minimum control value.

As the foundation of cloud theory, the cloud model is precisely both controlled and uncontrolled in microscope scale. $U$ is the time series of monitoring the dam deformation, and $C$ is the qualitative judgment on dam safety. If the quantitative value $x \in U, u(x)$ fall in $[0,1]$ and follow the probability distribution law:

$$
\mu: U \longrightarrow[0,1], \quad \forall x \in U, x \longrightarrow \mu(x)
$$

The distribution of $x$ in $U$ is called cloud and $(x, u)$ is the cloud droplet.

In Figure 2, for observation point $i$, if the range wherein the cloud droplet falls is given, the upper bound and lower bound of the cloud droplet in the cloud model $y_{i}^{u}$ and $y_{i}^{l}$ can be expressed as follows:

$$
\begin{gathered}
y_{i}^{u}\left(x_{i}, E x_{i}, E n_{i}, H e_{i}\right)=e^{-\left(x_{i}-E x_{i}\right)^{2} / 2\left(E n_{i}+3 H e_{i}\right)^{2}}, \\
y_{i}^{l}\left(x_{i}, E x_{i}, E n_{i}, H e_{i}\right)=e^{-\left(x_{i}-E x_{i}\right)^{2} / 2\left(E n_{i}-3 H e_{i}\right)^{2}} .
\end{gathered}
$$

$x_{i j}$ is the value $j$ of observation point $i$, and the fuzziness $\Delta_{i j}$ can be calculated by

$$
\Delta_{i j}=y_{i j}^{u}-y_{i j}^{l}
$$

In this equation, $y_{i j}^{u}$ is the upper limit value of $x_{i j}$ in the range and $y_{i j}^{l}$ is the lower limit value of $x_{i j}$ in the range.

Given the influence of random factors, when $x_{i j} \geq 0$, $x_{i j}$ changes in the range of $\left[x_{i j}-x_{i j} \Delta_{i j}, x_{i j}+x_{i j} \Delta_{i j}\right]$; when $x_{i j}<0$, it is in the range of $\left[x_{i j}+x_{i j} \Delta_{i j}, x_{i j}-x_{i j} \Delta_{i j}\right]$. When drawing up the warning indicator for downstream deformation, the maximum and minimum control values of the indicator can be determined when the significance level is $\alpha$; thus, indicating that the nondeterministic optimal control has been achieved.

\section{Methods of Characterizing Contributions of Single Observation Point}

The overall deformation condition of the concrete dam is usually exposed to the influences of water pressure and temperature and is related to many factors including the physical and mechanical properties of dam materials, body structure, geology, and hydrology and it could be referred to in Figure 3. The principles of synergetics posit that a concrete dam is a synthesis of feature points with different contributions (weights) that influence one another. The contribution of a single observation point needs to be studied to construct a reasonable expression of overall deformation.

3.1. Construction of the Indicator Set of a Single Observation Point Weight. Entropy [13-15], a basic concept in thermodynamics, refers to a state function in a system. The concept of information entropy is a measurement of the system's disorder and nondeterminacy [15]. The measured value $j$ on observation point $i$ is $x_{i j}$ and its corresponding entropy is $S_{i j}$. According to entropy theory, when an observation point is in a more dangerous state, the system is in greater disorder and its entropy value is smaller. Thus, the following is obtained:

$$
\begin{aligned}
& S_{i j}=-\left[\mu_{i j} \ln \mu_{i j}+\left(1-\mu_{i j}\right) \ln \left(1-\mu_{i j}\right)\right], \\
& \mu_{i j}=\left\{\begin{array}{l}
\int_{-\infty}^{x_{i j}} f(\varsigma) d \varsigma, \quad x_{i j} \geq 0 \\
\int_{x_{i j}}^{+\infty} f(\varsigma) d \varsigma, \quad x_{i j}<0 .
\end{array}\right.
\end{aligned}
$$

Formula (4) defines the information entropy of the measurement value. No matter what distribution $\left\{x_{i j}\right\}$ obeys, if the probability density function of the measured value is 

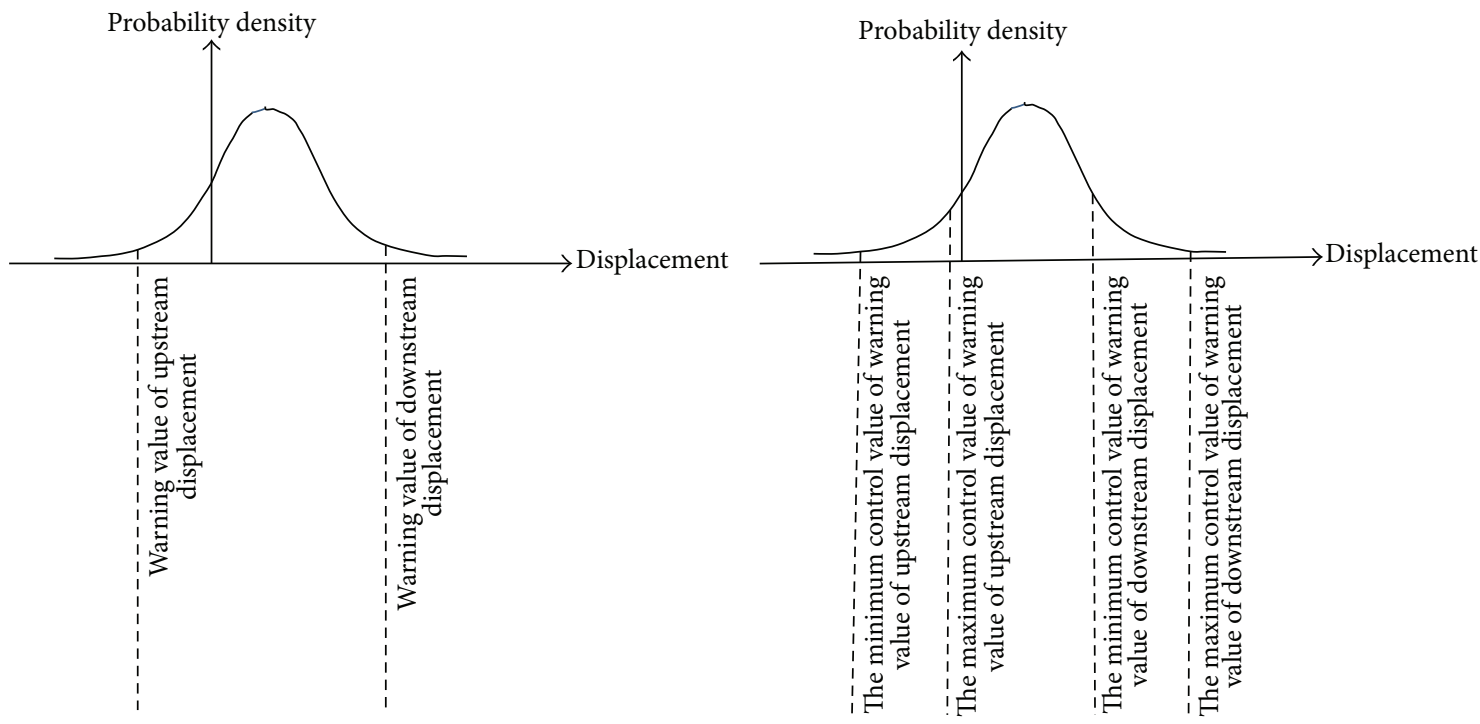

FIGURE 1: Diagram of deterministic optimal control and nondeterministic optimal control.

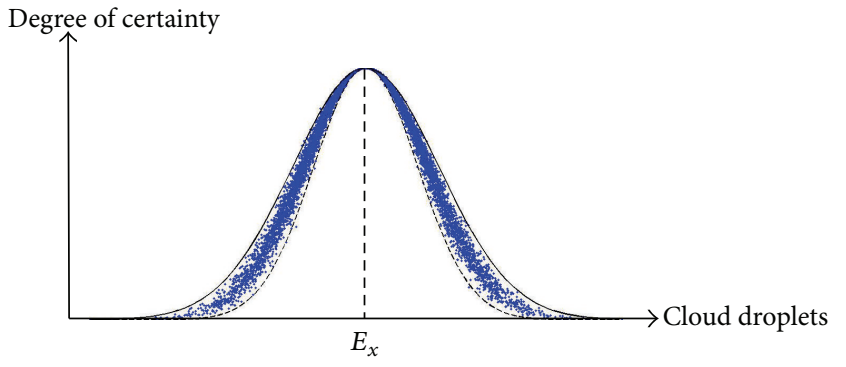

- Upper limit of cloud droplets

- - - Lower limit of cloud droplets

Figure 2: Diagram of the range where the cloud droplet falls.

known, the corresponding information entropy sequence can be calculated. Deformation of dam can be divided into three parts: water pressure component, temperature component, and aging component. Aging component comprehensively reflects the creep and plastic deformation of dam concrete and rock foundation and compression deformation of geological structure of rock foundation. At the same time, it also includes the irreversible displacement caused by the dam crack and the autogenous volume deformation. It changes dramatically in the early stage and gradually tends to be stable in the later stage. The project selected in this paper is a dam which has worked for many years, and its aging components tend to be stable, and the deformation value is stable in annual period rule, which obeys normal distribution.

The indicator measuring how much information is contained in $x_{i j}$ is the inverse entropy $D_{i j}: D_{i j}=1-S_{i j}$. When one measured value reflects more information, the entropy value $S_{i j}$ will be smaller and its inverse entropy $D_{i j}$ will be greater. Thus, $D_{i j}$ can be used to measure how much information is reflected by a single measured value.
Suppose the weight distribution of all observation points is $\left\{\omega_{i} \mid i=1,2, \ldots n\right\}$, where $n$ is the number of points observed and $\omega_{i}$ will meet the following requirement: $\omega_{i} \geq 0$ and $\sum \omega_{i}=1$. The entropy $S_{i j}$ of the object matrix of the deformation measured value $\left\{x_{i j} \mid i=1 \sim n, j=1 \sim m\right\}$ can be computed through (4) and (5). The inverse entropy matrix is expressed as follows:

$$
D_{i j}=\left[\begin{array}{cccc}
D_{11} & D_{12} & \cdots & D_{1 m} \\
D_{21} & D_{22} & \cdots & D_{2 m} \\
\vdots & \vdots & \vdots & \vdots \\
D_{n 1} & D_{n 2} & \cdots & D_{n m}
\end{array}\right] .
$$

In this matrix, $D_{i j}$ is the inverse entropy of $x_{i j}$. The weight of the feature points was traced by the projection pursuit method.

3.2. Process of Calculating the Weight of a Single Observation Point. By using the projection pursuit method [16, 17], the high-dimensional data can be projected to low dimension space, and projection that reflects the structure or features of high-dimensional data is pursued to analyze high-dimensional data. This method is advantageous because it is highly objective, robust, resistant to interference, and accurate. The steps are as follows.

Step 1. The extreme value of the inverse entropy matrix was normalized through the following equation:

$$
D_{i j}^{*}=\frac{D_{i j}-\left[D_{j}\right]_{\min }}{\left[D_{j}\right]_{\max }-\left[D_{j}\right]_{\min }},
$$

where $\left[D_{j}\right]_{\max }$ and $\left[D_{j}\right]_{\min }$ are the maximum and minimum values of line $j$ in the matrix, respectively. 


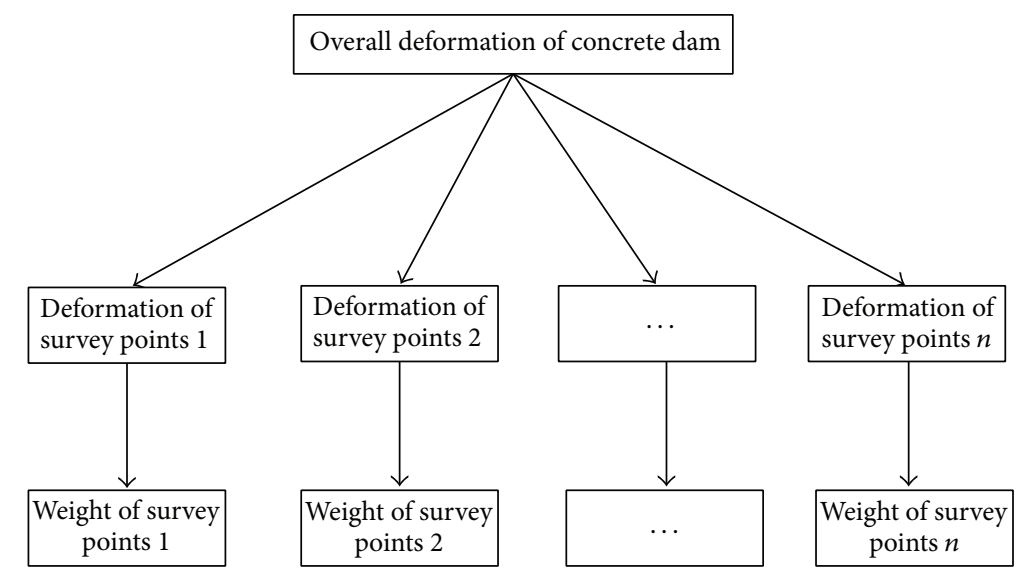

Figure 3: Diagram of overall deformation system of concrete dam.

Step 2. The normalized value $D_{i j}^{*}$ was projected to unit direction $P: P=\left(p_{1}, p_{2}, \ldots, p_{j}\right)$ and $p_{1}^{2}+p_{2}^{2}+\cdots+p_{j}^{2}=1$. The indicator function of the projection $G(i)$ was constructed:

$$
G(i)=\sum_{j=1}^{m} p_{j} D_{i j}^{*}, \quad(i=1,2, \ldots, n) .
$$

Step 3. The objective function of the projection was constructed. The best direction for the projection was estimated by solving the maximization problem of the objective function in the constraint condition:

$$
\begin{aligned}
& \text { Objective function: } \operatorname{Max}: H(p)=S_{G} \cdot Q_{G} \text {, } \\
& \text { Constraint condition: } \sum_{j=1}^{m} p_{j}^{2}=1 .
\end{aligned}
$$

In this equation, $S_{G}$ is the divergent degree of the projection. $Q_{G}$ is the local density of $1 D$ data points along $P$ and is expressed as follows:

$$
\begin{aligned}
S_{G} & =\left[\frac{\sum_{i=1}^{n}(G(i)-\bar{g}(i))^{2}}{n-1}\right]^{0.5} \\
Q_{G} & =\sum_{i=1}^{n} \sum_{j=1}^{n}\left(R-r_{i j}\right) \cdot f\left(R-r_{i j}\right),
\end{aligned}
$$

where $\bar{g}(i)$ is the mean value of this sequence, $R$ is the window radius of the local density and $R=0.1 S_{G}$ in this paper, $r_{i j}$ is the distance between two projection values, and $f(t)$ is the unit step function. $f(t)$ is equal to 1 as $t$ is greater than 0 . Otherwise, $f(t)$ is equal to 0 .

Step 4. The projection value of one sample point was computed by substituting the best direction $P^{*}$ into (8); $\omega_{i}$ can be calculated by normalizing the projection value:

$$
\omega_{i}=\frac{G^{*}(i)}{\sum_{j=1}^{n} G^{*}(j)}, \quad i=1,2, \ldots, n .
$$

\section{Study on Equivalent Model of Dam's Overall Deformation}

The overall deformation of a dam can be considered a deformation system of feature points with different contributions that influence one another, as well as observation points of the deformation as feature points. The deformation condition was analyzed systemically, and the overall deformation was expressed by the evolution of equation of all feature points. The deformation condition was described qualitatively by the tectonic type of information entropy. The absolute value of the information entropy measures the danger level of the deformation value. Smaller absolute value means higher danger level. The positive and negative values indicate the direction of the deformation. A positive value corresponds to downstream deformation, whereas a negative value corresponds to upstream deformation. The influences of random factors were considered and the fuzzy information entropy was constructed.

4.1. Constructing Fuzzy Information Entropy of Single Measured Value. The downstream deformation is positive, whereas the upstream deformation is negative.

When the observation point moves downstream, make $\mu_{i j}=\int_{-\infty}^{x_{i j}} f(\varsigma) d \varsigma$ and according to the definition of information entropy, the information entropy of $x_{i j}$ is expressed as (4).

Considering the influence of $\Delta_{i j}, \mu_{i j}$ will float in $\left[\mu_{i j}^{0}, \mu_{i j}^{1}\right]$; the following is then obtained:

$$
\begin{aligned}
& \mu_{i j}^{0}=\int_{-\infty}^{x_{i j}-x_{i j} \Delta_{i j}} f(\varsigma) d \varsigma, \\
& \mu_{i j}^{1}=\int_{-\infty}^{x_{i j}+x_{i j} \Delta_{i j}} f(\varsigma) d \varsigma .
\end{aligned}
$$

When the observation point moves upstream, make $\mu_{i j}=$ $\int_{x_{i j}}^{+\infty} f(\varsigma) d \varsigma$; the information entropy of $x_{i j}$ is defined as follows:

$$
S_{i j}=\mu_{i j} \ln \mu_{i j}+\left(1-\mu_{i j}\right) \ln \left(1-\mu_{i j}\right) .
$$




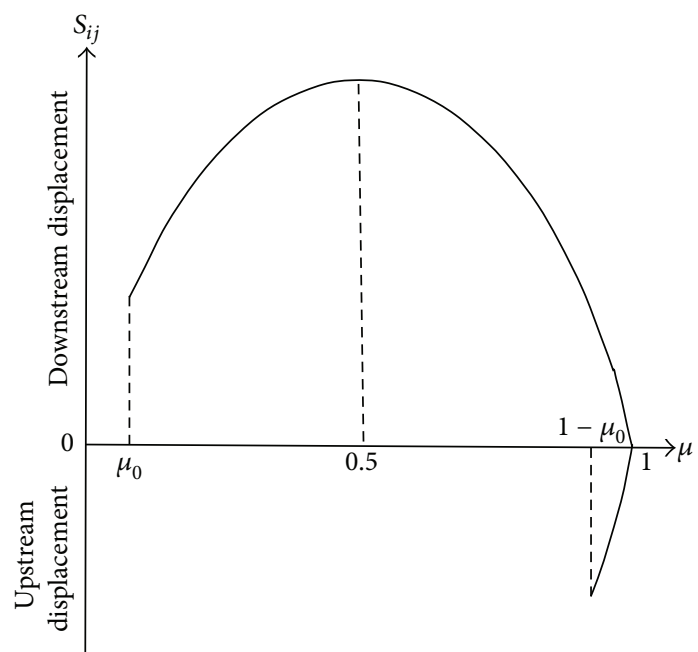

FIGURE 4: Diagram of $S_{i j}$ changes with the change of $\mu_{i j}$ if $E_{x} \geq 0$.

Considering the influence of $\Delta_{i j}, \mu_{i j}$ floats in $\left[\mu_{i j}^{0}, \mu_{i j}^{1}\right]$. The following is then obtained:

$$
\begin{aligned}
& \mu_{i j}^{0}=\int_{x_{i j}-x_{i j} \Delta_{i j}}^{+\infty} f(\varsigma) d \varsigma \\
& \mu_{i j}^{1}=\int_{x_{i j}+x_{i j} \Delta_{i j}}^{+\infty} f(\varsigma) d \varsigma .
\end{aligned}
$$

Considering the influences of random factors, the information entropy of $x_{i j}-S_{i j}$ floats in $\left[S_{i j}^{0}, S_{i j}^{1}\right]$, which was defined as the fuzzy information entropy of $x_{i j}$.

Take the downstream as an example. Influenced by determined and random factors, the fuzzy entropy of $S_{i j}$ changes into the range of $S_{i j}$ in the range of $\left[\mu_{i j}^{0}, \mu_{i j}^{1}\right]$.

4.2. Methods for Determining the Range of the Information Entropy of Single Measured Value. For Figure 4, the expectation of one deformation monitoring sequence sample at one observation point $\left(E_{x} \geq 0, S_{i j}\right)$ changes with the change of $\mu_{i j}$, as shown in Figure 4 , where $\mu_{0}=\int_{-\infty}^{0} f(\varsigma) d \varsigma$.

When the dam deforms downstream, the change law of $S_{i j}$ is as follows: $S_{i j}$ will increase with increasing $\mu_{i j}$ when $\mu_{i j}$ is in the range of $\left(\mu_{0}, 0.5\right) ; S_{i j}$ will decrease with decreasing $\mu_{i j}$ when $\mu_{i j}$ is in the range of $(0.5,1)$; when $\mu_{i j}=0.5, S_{i j}$ will reach the maximum value. If 0.5 is in the range of $\left[\mu_{i j}^{0}, \mu_{i j}^{1}\right]$, the maximum of $S_{i j}$ is $S_{i j}^{1}$ when $\mu_{i j}=0.5$ and its minimum value is $S_{i j}^{0}$ at the endpoint. If 0.5 is not in the range of $\left[\mu_{i j}^{0}, \mu_{i j}^{1}\right]$, $S_{i j}$ will have its maximum value $S_{i j}^{1}$ and minimum value $S_{i j}^{0}$ at endpoints. When the dam deforms upstream, $S_{i j}$ will rise with the rise of $\mu_{i j}$ and it will have its maximum value $S_{i j}^{1}$ and minimum value $S_{i j}^{0}$ at endpoints.

The expectation of one deformation monitoring sequence sample at one observation point $\left(E_{x}<0, S_{i j}\right)$ changes with

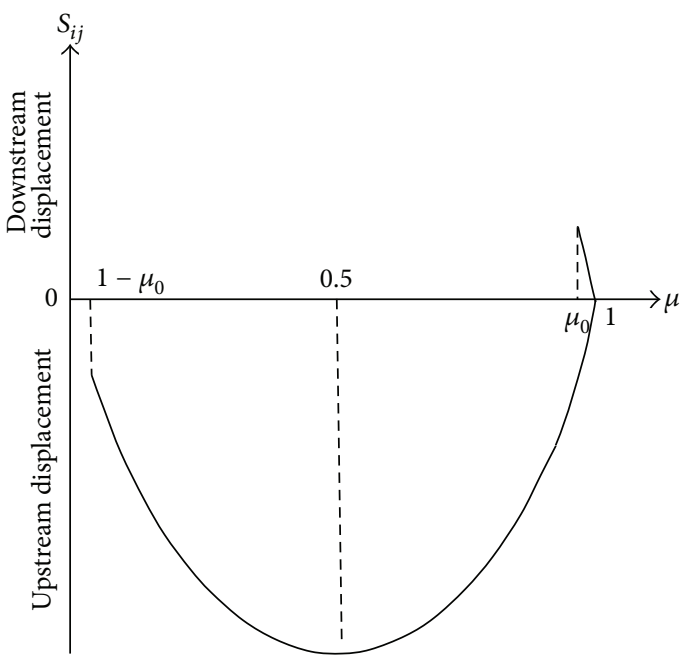

FIgURE 5: Diagram of $S_{i j}$ changes with the change of $\mu_{i j}$ if $E_{x}<0$.

the change of $\mu_{i j}$ as shown in Figure 5, where $\mu_{0}=\int_{-\infty}^{0} f(\varsigma) d \varsigma$ and Figure 5 is presented for $S_{i j}$ changes with the change of $\mu_{i j}$.

When the dam deforms downstream, the change law of $S_{i j}$ is as follows: $S_{i j}$ will increase with decreasing $\mu_{i j}$ and will have its maximum value $S_{i j}^{1}$ and minimum value $S_{i j}^{0}$ at endpoints. When the dam deforms upstream, the figure shows that when $\mu_{i j}$ is in the range of $\left(1-\mu_{0}, 0.5\right), S_{i j}$ will increase with the drop of $\mu_{i j}$; when $\mu_{i j}$ is in the range of $(0.5,1), S_{i j}$ will decrease with the increase of $\mu_{i j}$; when $\mu_{i j}=0.5, S_{i j}$ will reach the minimum value. If 0.5 is contained in the range of $\left[\mu_{i j}^{0}, \mu_{i j}^{1}\right], S_{i j}$ will have its minimum value $S_{i j}^{0}$ at $\mu_{i j}=0.5$ and have its maximum value $S_{i j}^{1}$ at endpoint; if 0.5 is not contained in the range, $S_{i j}$ will have its maximum value $S_{i j}^{1}$ and minimum value $S_{i j}^{0}$ at endpoints.

4.3. Construction of the Fuzzy Information Entropy of Overall Deformation. On the basis of the above results, the expression of information entropy of overall deformation can be deduced. The contribution of the order degree of observation point $i$ is $\omega_{i} \mu_{i j}$; make $\mu_{i j}^{1}=\mu_{i j}$ and $\mu_{i j}^{2}=1-\mu_{i j}$. According to the broad definition of information entropy, when the dam move deforms downstream, the expression of information entropy of overall deformation is expressed as follows:

$$
\begin{aligned}
S_{j} & =-\sum_{i=1}^{m} \sum_{k=1}^{2} \omega_{i} \mu_{i j}^{k} \ln \left(\omega_{i} \mu_{i j}^{k}\right) \\
& =-\sum_{i=1}^{n} \sum_{k=1}^{2} \omega_{i} \mu_{i j}^{k}\left(\ln \omega_{i}+\ln \mu_{i j}^{k}\right) \\
& =-\sum_{i=1}^{n} \sum_{k=1}^{2} \omega_{i} \mu_{i j}^{k} \ln \omega_{i}-\sum_{i=1}^{n} \sum_{k=1}^{2} \omega_{i} \mu_{i j}^{k} \ln \mu_{i j}^{k}
\end{aligned}
$$




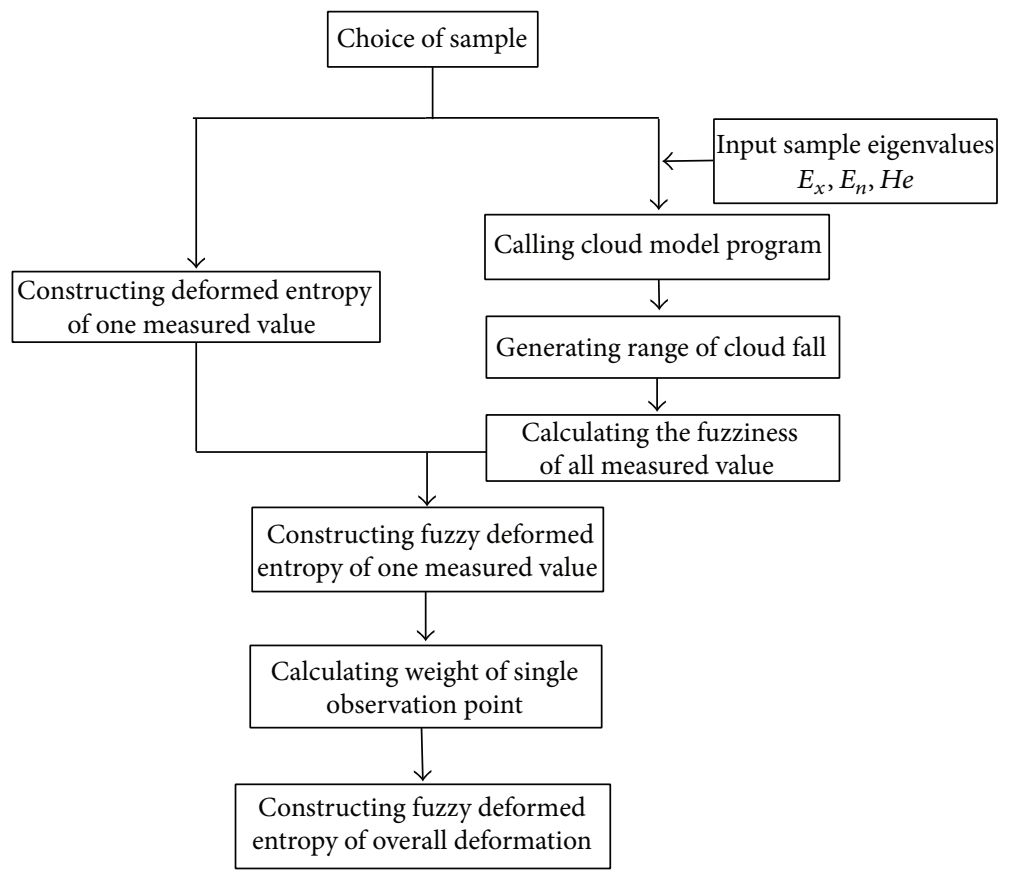

FIGURE 6: Computational process of fuzzy information entropy of overall deformation.

$$
\begin{aligned}
& =-\sum_{i=1}^{n} \omega_{i} \ln \omega_{i} \sum_{k=1}^{2} \mu_{i j}^{k}-\sum_{i=1}^{n} \omega_{i} \sum_{k=1}^{2} \mu_{i j}^{k} \ln \mu_{i j}^{k} \\
& =-\sum_{i=1}^{n} \omega_{i} \ln \omega_{i}+\sum_{i=1}^{n} \omega_{i} S_{i j} .
\end{aligned}
$$

When the dam move deforms upstream, the expression of the information entropy of overall deformation is

$$
S_{j}=\sum_{i=1}^{m} \sum_{k=1}^{2} \omega_{i} \mu_{i j}^{k} \ln \left(\omega_{i} \mu_{i j}^{k}\right)=\sum_{i=1}^{n} \omega_{i} \ln \omega_{i}+\sum_{i=1}^{n} \omega_{i} S_{i j} .
$$

Therefore, the expression of information entropy of overall deformation is defined as follows:

$$
S_{j}= \begin{cases}-\sum_{i=1}^{n} \omega_{i} \ln \omega_{i}+\sum_{i=1}^{n} \omega_{i} S_{i j}, & S_{i j} \geq 0 \\ \sum_{i=1}^{n} \omega_{i} \ln \omega_{i}+\sum_{i=1}^{n} \omega_{i} S_{i j}, & S_{i j}<0\end{cases}
$$

The absolute value of the information entropy of the overall deformation measures the danger level of the deformation; that is, a smaller absolute value means a higher danger level; positive and negative values stand for the direction of the deformation: a positive value means downstream deformation, whereas a negative value means upstream deformation.

Considering the influences of random factors, the fuzzy information entropy of $x_{i j}$ is $\left[S_{i j}^{0}, S_{i j}^{1}\right]$; the fuzzy information entropy of overall deformation can be illustrated through (17). Computational process of fuzzy information entropy of overall deformation is shown in Figure 6.

\section{Proposed Multistage Fuzzy Information Entropy of Overall Deformation Warning Indicators}

Horizontal displacement of dam crest changes in an annual cycle: "upstream and downstream switch." Therefore, this displacement should be in a certain scale and be controlled under some monitoring indicators for the safe dam operation.

In the case of downstream displacement, the primary fuzzy warning indicator $\delta_{1}^{\prime}$ is defined as $\delta_{1}^{\prime}=\left(\delta_{1}^{0}, \delta_{1}^{1}\right)$. $\delta_{1}^{0}$ is the lower limit of this indicator, and $\delta_{1}^{1}$ is the upper limit; the secondary indicator $\delta_{2}^{\prime}$ is $\delta_{2}^{\prime}=\left(\delta_{2}^{0}, \delta_{2}^{1}\right)$, where $\delta_{2}^{0}$ is the lower limit of this indicator and $\delta_{2}^{1}$ is the upper limit. When $\delta_{1}^{1}>\delta_{2}^{0}$, a cross phenomenon appears in the primary indicator and secondary indicator, when both of them should be categorized according to the membership of displacement measured. $\delta^{*}$ was introduced because the membership of displacement at this point is the same. Figure 7 shows diagram of multistage fuzzy information entropy warning indicators.

The primary fuzzy warning indicator is $\delta_{1}^{\prime}=\left(\delta_{1}^{0}, \delta^{*}\right)$, and the secondary is $\delta_{2}^{\prime}=\left(\delta^{*}, \delta_{2}^{1}\right)$.

If the deformation value is in $\left(\delta_{1}^{0}, \delta_{1}^{1}\right)$ or $\left(\delta_{1}^{0}, \delta^{*}\right)$, the dam is in the state of primary warning; if the value is in $\left(\delta_{2}^{0}, \delta_{2}^{1}\right)$ or $\left(\delta_{2}^{0}, \delta^{*}\right)$, the dam is in the state of secondary warning.

The time sequence of deformation at each observation point was analyzed by using the above theoretical method. The lower and upper limits of the fuzzy information entropy of overall deformation affected by $\Delta_{i j}$ will be $\left\{S_{j}^{0}\right\}$ and $\left\{S_{j}^{1}\right\}$. Considering the dam's long-term service, when the dam moves downstream, the lower limit $\left\{S_{m j}^{0}\right\}$ and upper limit 


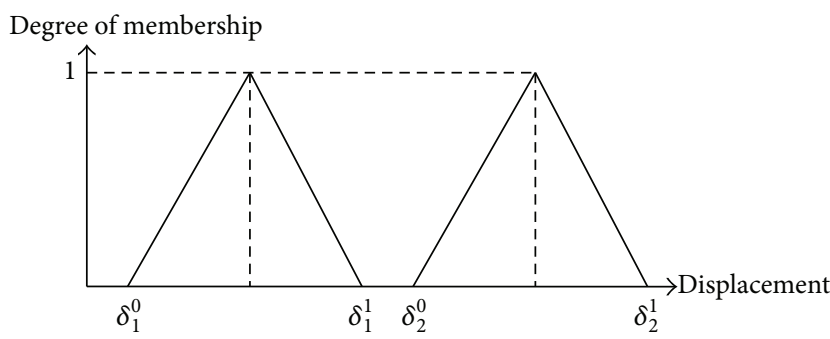

Degree of membership

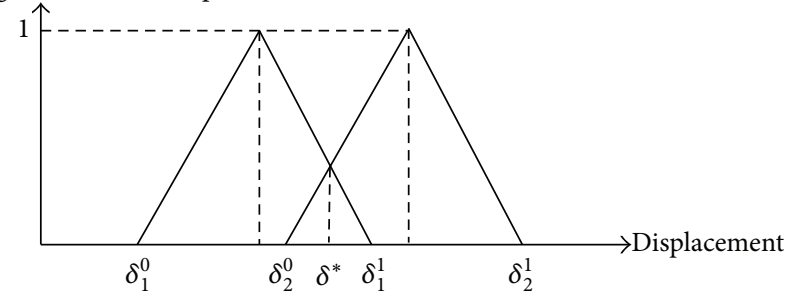

FIGURE 7: Diagram of multistage fuzzy information entropy warning indicators.

$\left\{S_{m j}^{1}\right\}$ were selected and when the dam moves upstream, the lower limit $\left\{R_{m j}^{0}\right\}$ and upper limit $\left\{R_{m j}^{1}\right\}$ were selected. $\left\{S_{m j}^{0}\right\},\left\{S_{m j}^{1}\right\},\left\{R_{m j}^{0}\right\}$, and $\left\{R_{m j}^{1}\right\}$ are random variables, and four subsample spaces with the sample size of $N$ can be obtained by the following:

$$
\begin{aligned}
S^{0} & =\left\{S_{m 1}^{0}, S_{m 2}^{0}, \ldots, S_{m m}^{0}\right\} \\
S^{1} & =\left\{S_{m 1}^{1}, S_{m 2}^{1}, \ldots, S_{m m}^{1}\right\} \\
R^{0} & =\left\{R_{m 1}^{0}, R_{m 2}^{0}, \ldots, R_{m m}^{0}\right\} \\
R^{1} & =\left\{R_{m 1}^{1}, R_{m 2}^{1}, \ldots, R_{m m}^{1}\right\} .
\end{aligned}
$$

Shapiro-Wilk test and Kolmogorov-Smirnov test can both test whether the samples obey normal distribution or not. But the Kolmogorov-Smirnov test is applicable to fewer samples. It can not only test if the samples are subject to normal distribution, but also test if samples are subject to other distributions. The basic idea of the K-S test is to compare the cumulative frequency of the observed value $\left(F_{n}(x)\right)$ with the assumed theoretical probability distribution $\left(F_{x}(x)\right)$ to construct statistics.

According to the method of empirical distribution function, segmented cumulative frequency is obtained by using the following formula:

$$
F_{n}(x)= \begin{cases}0, & x<x_{i} \\ \frac{i}{n}, & x_{i} \leq x<x_{i+1} \\ 1, & x \geq x .\end{cases}
$$

In the formula, $x_{1}, x_{2}, \ldots, x_{n}$ is sample data after arrangement. The sample size is $n$.
In the full range of random variable $X$, the maximum difference between $F_{n}(x)$ and $F_{x}(x)$ is

$$
D_{n}=\max \left|F_{x}(x)-F_{n}(x)\right|<D_{n}^{\beta} .
$$

In the formula, $D_{n}$ is a random variable whose distribution depends on $n . D_{n}^{\beta}$ is critical value for a significant level $\beta$. It is considered that the distribution to be used at a significant level $\beta$ cannot be resisted; otherwise, it should be rejected.

The distribution form was tested through the K-S method to determine the probability density function. Fuzzy warning indicator was then determined with different significant level. In dam safety evaluation, significant level $\alpha$ is the probability of the dam failure. Supposing $S_{m}$ is the extreme of the information entropy of the upstream overall deformation, if $S>S_{m}$, the probability of the dam failure is $P\left(S>S_{m}\right)=$ $\alpha=\int_{S_{m}}^{\infty} f(x) d x$ and the reliability index of dam failure is $1-\alpha$. According to the dam importance, different failure probability is set and the multistage warning indicators were identified.

\section{Example Analysis}

6.1. Project Profile. One flat-slab deck dam built with reinforced concrete is an important part of one river basin cascade exploitation. The elevation of this dam crest is $137.70 \mathrm{~m}$, and the height of biggest part is about $43 \mathrm{~m}$; the crest runs $225.0 \mathrm{~m}$ in length and is made of 27 flat-slab buttresses with a span of $7.5 \mathrm{~m}$. The space between the left side of 2\# buttress and the right side of 9 \# buttress is the joint part; the overflow buttress is located from the $9 \#$ buttress to the 20\# buttress; the rest is the water-retaining buttress. The workshop buttress is located from the $5 \#$ buttress to the 8\# buttress. In this dam, the level of dead water is $122.0 \mathrm{~m}$, the normal high water level is $131.0 \mathrm{~m}$ (in practice, it is $129.0 \mathrm{~m}$ ), the design flood level is $136.7 \mathrm{~m}$, and the check flood level is $137.5 \mathrm{~m}$. To monitor the displacement of this dam, a direct plumb line and an inverted plumb line were arranged in four buttresses: $4 \#, 9 \#, 21 \#$, and $24 \#$. There is a crushed zone under the dam foundation where occurrence is $\mathrm{N} 20^{\circ} \sim 25^{\circ} \mathrm{W}, \mathrm{SW} \angle 70^{\circ} \sim 80^{\circ}$, the maximum width is about $3 \mathrm{~m}$, and the narrowest place is about $1 \mathrm{~m}$. There is an elevation clip joint mud at level $91 \mathrm{~m}$.

The deformation field characterized by the observation point at $21 \#$ should be typical and is a key point because it is in the riverbed. Thus, the observation point G21 at the height of $134 \mathrm{~m}$ along the direct plumb line at $21 \#$ was analyzed, as well as point 27 at the height of $118 \mathrm{~m}$ along this line and point 28 at the height of $107 \mathrm{~m}$. All these values measured were transformed into absolute displacement. The arrangement of each point is shown in Figure 8. The daily monitoring data series is from January 1, 2003, to December 31, 2013.

In this paper, two-stage warning indicators were set according to the practical running of this project and danger: $\alpha=5 \%$ is the primary warning that is mainly used to discriminate and handle early dangerous case and the reliability index of dam failure is $95 \%$, whereas $\alpha=1 \%$ is the secondary warning that is mainly used to determine grave danger and prevent urgent danger and the reliability index of dam failure is $99 \%$. 


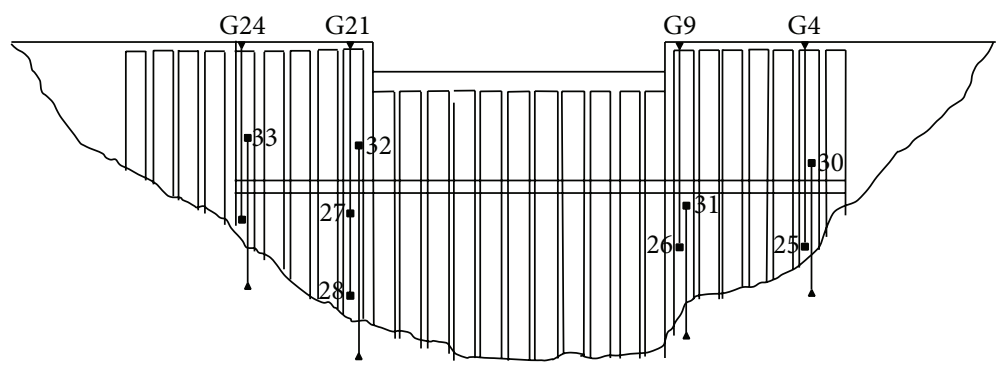

FIGURE 8: The arrangement of observation point.

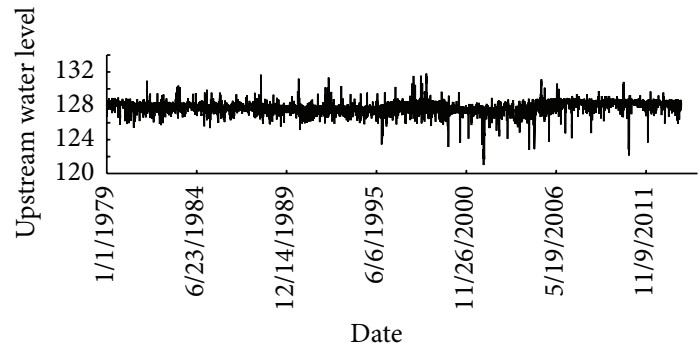

Figure 9: The process line of upstream water level.

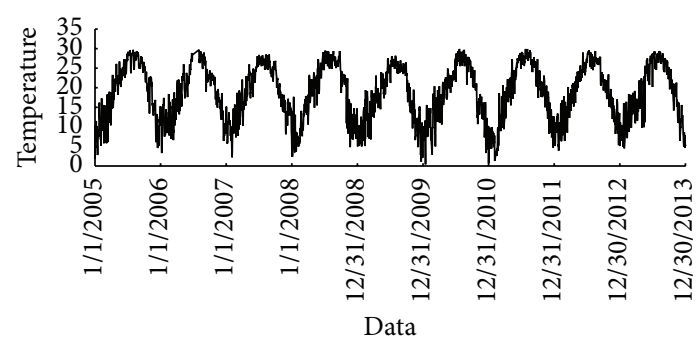

FIGURE 10: The process line of temperature.

6.2. Calculating the Contribution of Deformation at the Observation Point to the Overall Deformation. Figures 910 show the upstream stage hydrograph and temperature stage hydrograph, respectively. The water stage remained unchanged, whereas the temperature changed in the annual cycle. Figure 11 shows the relationship between information entropy of overall deformation and temperature in 2007. A negative correlation exists between the overall deformation of 21 \# buttress and temperature; that is, an increase in temperature corresponds to the decrease in upstream or downstream displacement and a decrease in temperature means an increase in the upstream or downstream displacement. Figure 12 shows the correlation between the displacement at observation point G21 and the temperature. The overall deformation law is roughly identical with that at observation point G21.

Figure 12 reveals that the temperature obviously influenced overall deformation; that is, the temperature can change the contribution of single observation point to the overall deformation. Temperature change was divided into the stage of temperature rise and stage of temperature drop.

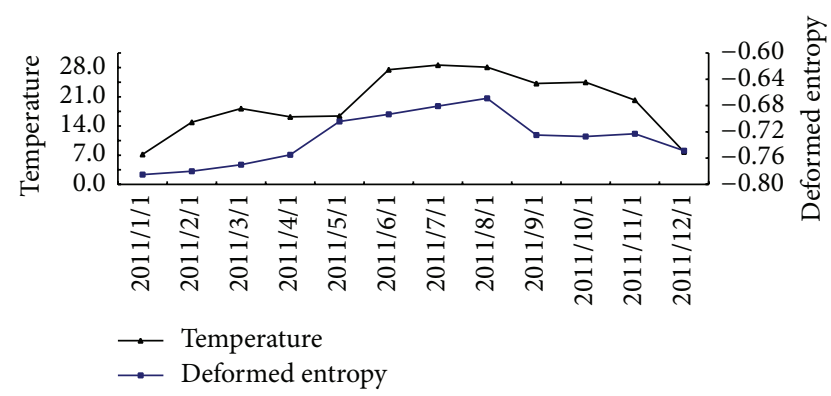

FIGURE 11: The relationship between information entropy of overall deformation and temperature in 2011.

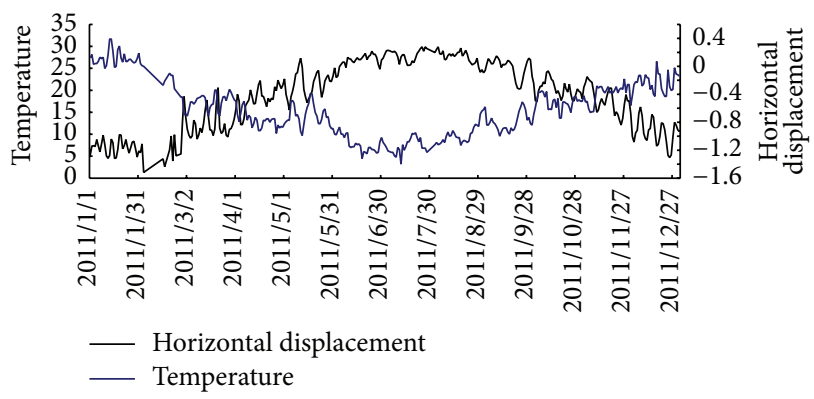

FIGURE 12: The relationship between horizontal displacement and temperature of observation point G21 in 2011.

The weight of deformation at observation point in two stages was calculated. The results are shown in the Table 1.

6.3. Results of Information Entropy of Overall Deformation. Range of cloud fall of the displacement at G21, 27, and 28 is shown in Figure 13. The boundary values of most dangerous information entropy from 2003 to 2013 are shown in Tables 2-5. The absolute value means the degree of danger; downstream is set as negative value. In the significance level $\alpha=0.05,7$ kinds of common distribution (lognormal distribution, normal distribution, uniform distribution, triangular distribution, exponential distribution, $\gamma$ distribution, and $\beta$ distribution) were used to carry on hypothesis test for $\left\{S_{m j}^{0}\right\}$, $\left\{S_{m j}^{1}\right\},\left\{R_{m j}^{0}\right\}$, and $\left\{R_{m j}^{1}\right\}$ with K-S method. The maximum $D_{n}$ of each sequence was obtained and compared with the critical value $D_{n}^{0.05}$ of the significant level 0.05 to determine the type 
TABLE 1: The weight table of observation point.

\begin{tabular}{lccc}
\hline Observation point & Altitude & The period of temperature rise & The period of temperature drop \\
\hline G21 & $134 \mathrm{~m}$ & 0.357 & 0.392 \\
27 & $118 \mathrm{~m}$ & 0.331 & 0.316 \\
28 & $107 \mathrm{~m}$ & 0.312 & 0.292 \\
\hline
\end{tabular}

TABLE 2: The lower limit of the most dangerous information entropy of downstream overall deformation.

\begin{tabular}{lccccccccccc}
\hline Year & 2003 & 2004 & 2005 & 2006 & 2007 & 2008 & 2009 & 2010 & 2011 & 2012 & 2013 \\
\hline Information entropy & 0.4784 & 0.4837 & 0.4767 & 0.4784 & 0.4969 & 0.4887 & 0.4969 & 0.5102 & 0.5082 & 0.4799 & 0.4739 \\
\hline
\end{tabular}

TABLE 3: The upper limit of the most dangerous information entropy of downstream overall deformation.

\begin{tabular}{lccccccccccc}
\hline Year & 2003 & 2004 & 2005 & 2006 & 2007 & 2008 & 2009 & 2010 & 2011 & 2012 & 2013 \\
\hline Information entropy & 0.4791 & 0.4845 & 0.4770 & 0.4786 & 0.4971 & 0.4899 & 0.4974 & 0.5186 & 0.5161 & 0.4817 & 0.4769 \\
\hline
\end{tabular}

TABLE 4: The lower limit of the most dangerous information entropy of upstream overall deformation.

\begin{tabular}{lccccccccccc}
\hline Year & 2003 & 2004 & 2005 & 2006 & 2007 & 2008 & 2009 & 2010 & 2011 & 2012 & 2013 \\
\hline Information entropy & -0.5433 & -0.5491 & -0.4773 & -0.5083 & -0.5067 & -0.4784 & -0.5080 & -0.4839 & -0.4836 & -0.4825 & -0.5020 \\
\hline
\end{tabular}

TABLE 5: The lower limit of the most dangerous information entropy of upstream overall deformation.

\begin{tabular}{lccccccccccc}
\hline Year & 2003 & 2004 & 2005 & 2006 & 2007 & 2008 & 2009 & 2010 & 2011 & 2012 & 2013 \\
\hline Information entropy & -0.5339 & -0.5440 & -0.4770 & -0.5079 & -0.5055 & -0.4770 & -0.5040 & -0.4822 & -0.4806 & -0.4754 & -0.4766 \\
\hline
\end{tabular}

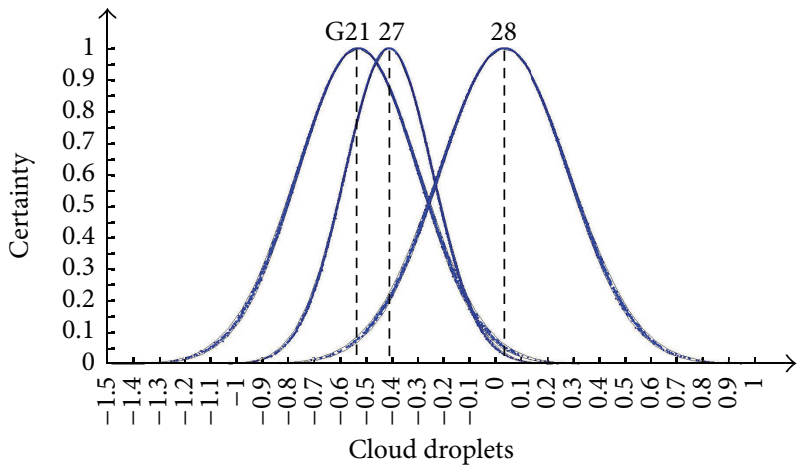

FIGURE 13: Range of cloud fall of the displacement at G21, 27, and 28.

of the best distribution. K-S test results are shown in Table 6. Multistage fuzzy warning values are presented in Table 7.

K-S test shows that $\left\{S_{m j}^{0}\right\},\left\{S_{m j}^{1}\right\},\left\{R_{m j}^{0}\right\}$, and $\left\{R_{m j}^{1}\right\}$ satisfy normal distribution.

The probability density function of the sequence is

$$
f(x)=\frac{1}{\sqrt{2 \pi} \sigma^{2}} \exp \left(-\frac{(x-\mu)^{2}}{\sigma}\right) .
$$

Parameter values of (21) are presented in Table 7.

In downstream deformation, if $\alpha=5 \%$, the primary warning indicator is $(0.4763,0.4775)$; if $\alpha=1 \%$, the secondary warning indicator is $(0.4757,0.4763) . \delta^{*}$ is used as the boundary value when two indicators overlap. In the case of upstream deformation, if $\alpha=5 \%$, the primary warning indicator is $(-0.4779,-0.4768)$; if $\alpha=1 \%$, the secondary warning indicator is $(-0.4768,-0.4763)$ (Table 8$)$.

6.4. The Structure Calculation of Monitoring Index of Dam Horizontal Displacement. According to the actual situation, three-dimensional finite element model of the dam is established. According to the structure and basic geological conditions of $21 \#$ dam section, the scope of finite element calculation model can be got as follows: taking 1.5 times as high dam in the upstream direction, taking 1.5 times as high dam in the upstream direction, and taking 1 time as high dam below the dam foundation. The model is constituted of 11445 nodes and 8571 units. The unit type is 6 sides 8 nodes isoparametric element. The deformation observation data analysis shows the dam under the condition of low temperature and high water level: there is larger displacement in the downstream when in high temperature, and in low water level, there is larger displacement in the upstream (Table 9, Figure 14). In view of the actual situation of the dam observation and data analysis results, the load condition selection is as follows (Table 10, Figures 15 and 16):

Working condition 1: normal water level $129.0 \mathrm{~m}$ and maximum temperature drop.

Working condition 2: dead water level $122.0 \mathrm{~m}$ and maximum temperature rise. 
TABLE 6: K-S test results.

\begin{tabular}{lcccc}
\hline Probability distribution & $S_{m j}^{0}$ & $S_{m j}^{1}$ & $R_{m j}^{0}$ & $R_{m j}^{1}$ \\
\hline Lognormal distribution & 0.26 & 0.11 & 0.23 & 0.28 \\
Normal distribution & 0.11 & 0.08 & 0.26 & 0.22 \\
Uniform distribution & 0.74 & 1.55 & 0.59 & 0.68 \\
Triangular distribution & 0.53 & 0.54 & 0.55 & 0.61 \\
Exponential distribution & 0.41 & 0.42 & 0.31 & 0.35 \\
$\gamma$ distribution & 0.37 & 0.36 & 0.86 & 0.33 \\
$\beta$ distribution & 0.68 & 0.73 & 0.29 & 0.63 \\
$D_{n}^{0.05}$ & 0.34 & 0.34 & Normal distribution & Normal distribution \\
The most reasonable probability distribution & Normal distribution & Normal distribution & Norma \\
\hline
\end{tabular}

TABLE 7: Parameter values of the probability density function.

\begin{tabular}{lcc}
\hline Data series & \multicolumn{2}{c}{ Parameter values } \\
& $\mu$ & $\sigma^{2}$ \\
$\left\{S_{m j}^{0}\right\}$ & 0.488355 & 0.0129 \\
$\left\{S_{m j}^{1}\right\}$ & 0.490627 & 0.0151 \\
$\left\{R_{m j}^{0}\right\}$ & -0.50210 & 0.0249 \\
$\left\{R_{m j}^{1}\right\}$ & -0.49674 & 0.0245 \\
\hline
\end{tabular}

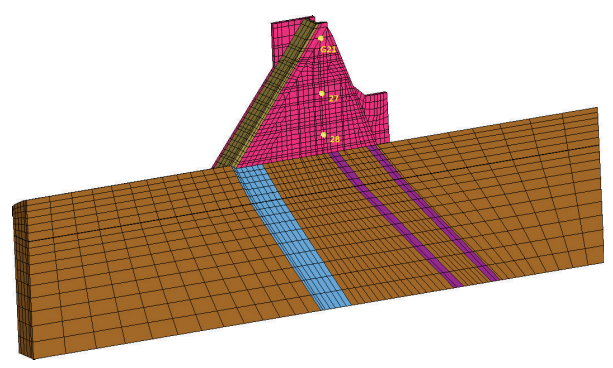

FIgURE 14: Finite element model of the dam.

The primary warning indicators of concrete dam were obtained by calculation methods for structures. If the information entropy of the overall deformation reached 0.4770 , the dam moved downstream and in the state of primary warning. If the information entropy of the overall deformation reached -0.4773 , the dam moved upstream and in the state of primary warning (Table 11). They all fell into intervals calculated by fuzzy methodology. The analysis shows that the method brought up in this paper is reasonable and scientific. Also, the analysis shows the physical meaning of the fuzzy warning index. Under the action of the unfavorable load combination and the influence of the complex random factors, the maximum entropy and minimum information entropy of the overall deformation lie in this interval. Considering the influences of random factors, multistage fuzzy warning values were receptive and safe.

In this paper, the overall deformation of $21 \#$ buttress was analyzed through the theoretical method proposed. Influences of random factors on the warning value were considered and multistage fuzzy warning values were determined. If the information entropy of overall deformation is in $(0.4763,0.4775)$, the dam moved downstream and in

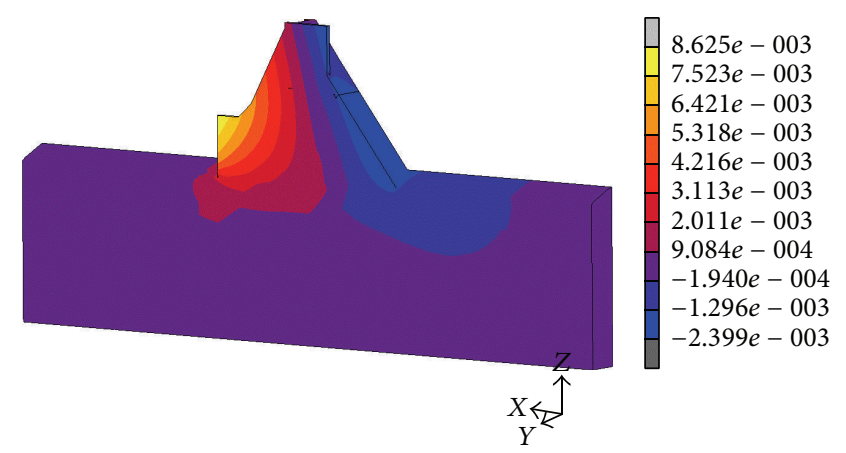

FIGURE 15: The results of finite element calculation of working condition 1.

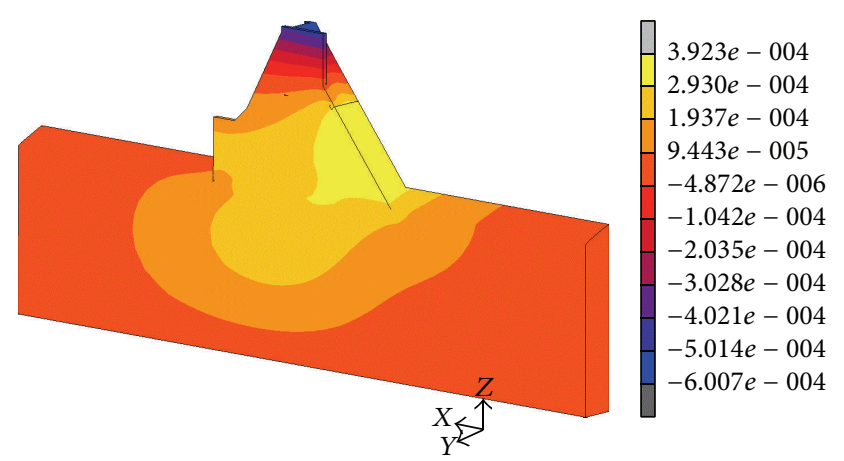

FIGURE 16: The results of finite element calculation of working condition 2 .

the state of primary warning. If the information entropy of overall deformation is in $(0.4757,0.4763)$, the dam moved downstream and in the state of secondary warning. If the information entropy of overall deformation is in $(-0.4779$, $-0.4768)$, the dam moved upstream and in the state of primary warning. If the information entropy of the overall deformation is in $(-0.4768,-0.4763)$, the dam moved upstream and in the state of secondary warning.

\section{Conclusion}

This paper presented multistage warning indicators of concrete dam space and considered the influences of complex 
TABLE 8: Multistage fuzzy warning values of concrete dam.

\begin{tabular}{lcc}
\hline The direction of deformation & Confidence level & \\
& The primary warning indicator & The secondary warning indicator \\
\hline Downstream & $(0.4763,0.4775)$ & $(0.4757,0.4763)$ \\
Upstream & $(-0.4779,-0.4768)$ & $(-0.4768,-0.4763)$ \\
\hline
\end{tabular}

TABLE 9: Material parameter of the dam.

\begin{tabular}{lccc}
\hline Structure & Density $(\mathrm{kg} / \mathrm{m})$ & Poisson's ratio & Elastic modulus $(\mathrm{GPa})$ \\
\hline Concrete face slab & 2400 & 0.167 & 24 \\
Buttress & 2400 & 0.167 & 24 \\
Partition wall & 2400 & 0.167 & 24 \\
Reinforced concrete block & 2400 & 0.160 & 22 \\
Foundation rock mass & 2700 & 0.175 & 12 \\
Diorite-dyke & 2000 & 0.3 & 1.15 \\
Crushed zone & 2000 & 0.3 & 0.29 \\
Horizontal joints & 2000 & 0.3 & 0.7 \\
\hline
\end{tabular}

TABLE 10: The results of finite element calculation of displacement of observation point ( $\mathrm{mm})$.

\begin{tabular}{lcc}
\hline Observation point & Working condition 1 & Working condition 2 \\
\hline G21 & 0.785 & -0.599 \\
27 & 0.654 & -0.386 \\
28 & 0.356 & 0.114 \\
\hline
\end{tabular}

TABLE 11: The primary warning indicators of concrete dam.

\begin{tabular}{lc}
\hline The direction of deformation & The primary warning indicator \\
\hline Downstream & 0.4770 \\
Upstream & -0.4773 \\
\hline
\end{tabular}

random factors. The results of the specific studies are as follows:

(1) Influences of fuzziness and randomness of random factors on the long-term service of dam were discussed; a fuzziness indicator that measures the influence of random factors on monitoring value was constructed through cloud model.

(2) Equivalent model of overall deformation was proposed. In the model, the overall deformation of dam was regarded as a deformation system where each observation point had different contributions (weights) and affected one another. Based on entropy theory, a space information entropy that can measure the overall deformation condition was established.

(3) Multistage warning indicators against overall deformation of concrete dam under the influences of fuzziness and randomness were determined and nondeterministic optimal control of the indicator was achieved to improve the competence of warning against the deformation of concrete dam.

\section{Competing Interests}

No conflict of interests exits in the submission of this paper.

\section{Acknowledgments}

This paper was financially supported by National Natural Science Foundation of China (Grants nos. 41323001, 51139001, 51579086, 51379068, 51279052, 51579083, and 51209077), Jiangsu Natural Science Foundation (Grants nos. BK20140039 and BK2012036), Research Fund for the Doctoral Program of Higher Education of China (Grant no. 20130094110010), the Ministry of Water Resources Public Welfare Industry Research Special Fund Project (Grants nos. 201201038 and 201301061), Jiangsu Province "333 HighLevel Personnel Training Project" (Grants nos. BRA2011179 and BRA2011145), Project Funded by the Priority Academic Program Development of Jiangsu Higher Education Institutions (Grant no. YS11001), Jiangsu Province "333 High-Level Personnel Training Project” (Grant no. 2017-B08037), Jiangsu Province "Six Talent Peaks" Project (Grant no. JY-008), and Fundamental Research Funds for the Central Universities (Grants nos. 2016B04114 and 2015B25414).

\section{References}

[1] F. Benedetto, G. Giunta, and L. Mastroeni, "A maximum entropy method to assess the predictability of financial and commodity prices," Digital Signal Processing, vol. 46, pp. 19-31, 2015.

[2] S. Muraro, A. Madaschi, and A. Gajo, "On the reliability of 3D numerical analyses on passive piles used for slope stabilisation in frictional soils," Geotechnique, vol. 64, no. 6, pp. 486-492, 2014.

[3] W. J. Yoon and K. S. Park, "A study on the market instability index and risk warning levels in early warning system for economic crisis," Digital Signal Processing, vol. 29, pp. 35-44, 2014.

[4] D. Tonini, "Observed behavior of several leakier arch dams," Journal of the Power Division, vol. 82, no. 12, pp. 135-139, 1956. 
[5] R. Salgado and D. Kim, "Reliability analysis of load and resistance factor design of slopes," Journal of Geotechnical and Geoenvironmental Engineering, vol. 140, no. 1, pp. 57-73, 2014.

[6] Y. C. Gu and S. J. Wang, "Study on the early-warning threshold of structural instability unexpected accidents of reservoir dam," Journal of Hydraulic Engineering, vol. 40, no. 12, pp. 1467-1472, 2009.

[7] H. Z. Su, F. Wang, and H. P. Liu, "Early-warning index for dam service behavior based on POT model," Journal of Hydraulic Engineering, vol. 43, no. 8, pp. 974-986, 2012.

[8] L. Chen, Mechanics performance with parameters changing in space \& monitoring model of roller compacted concrete dam [Ph.D. thesis], Hohai University, 2006.

[9] A. B. Li, L. F. Zhang, Q. L. Wang, B. Li, Z. Li, and Y. Wang, "Information theory in nonlinear error growth dynamics and its application to predictability: taking the Lorenz system as an example," Science China Earth Sciences, vol. 56, no. 8, pp. 14131421, 2013.

[10] O. Victor, “The theory of clouds," Library Journal, vol. 132, no. 13, p. 62, 2007.

[11] M. Yang, H. Z. Su, and X. Q. Yan, "Computation and analysis of high rocky slope safety in a water conservancy project," Discrete Dynamics in Nature and Society, vol. 2015, Article ID 197579, 11 pages, 2015.

[12] C. Ricotta and G. C. Avena, "Evaluating the degree of fuzziness of thematic maps with a generalized entropy function: a methodological outlook," International Journal of Remote Sensing, vol. 23, no. 20, pp. 4519-4523, 2002.

[13] V. I. Khvorostyanov and J. A. Curry, "Parameterization of homogeneous ice nucleation for cloud and climate models based on classical nucleation theory," Atmospheric Chemistry and Physics, vol. 12, no. 19, pp. 9275-9302, 2012.

[14] H. Z. Su, Z. P. Wen, and Z. R. Wu, "Study on an intelligent inference engine in early-warning system of damhealth," Water Resources Management, vol. 25, no. 6, pp. 1545-1563, 2011.

[15] M. Kamiński, "Probabilistic entropy in homogenization of the periodic fiber-reinforced composites with random elastic parameters," International Journal for Numerical Methods in Engineering, vol. 90, no. 8, pp. 939-954, 2012.

[16] E. Czogała and J. Łęski, "Application of entropy and energy measures of fuzziness to processing of ECG signal," Fuzzy Sets and Systems, vol. 97, no. 1, pp. 9-18, 1998.

[17] K. Wu and J. L. Jin, "Projection pursuit model for evaluation of region water resource security based on changeable weight and information," Resources and Environment in the Yangtze Basin, vol. 20, no. 9, pp. 1085-1091, 2011. 


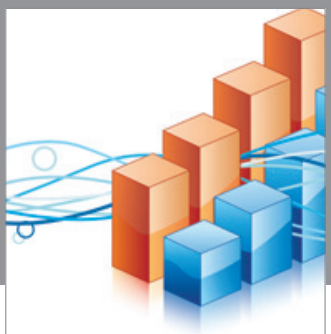

Advances in

Operations Research

vatem alat4

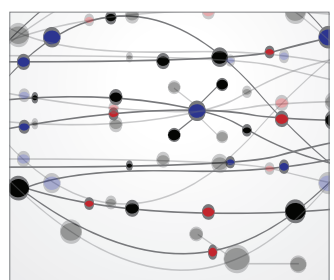

\section{The Scientific} World Journal
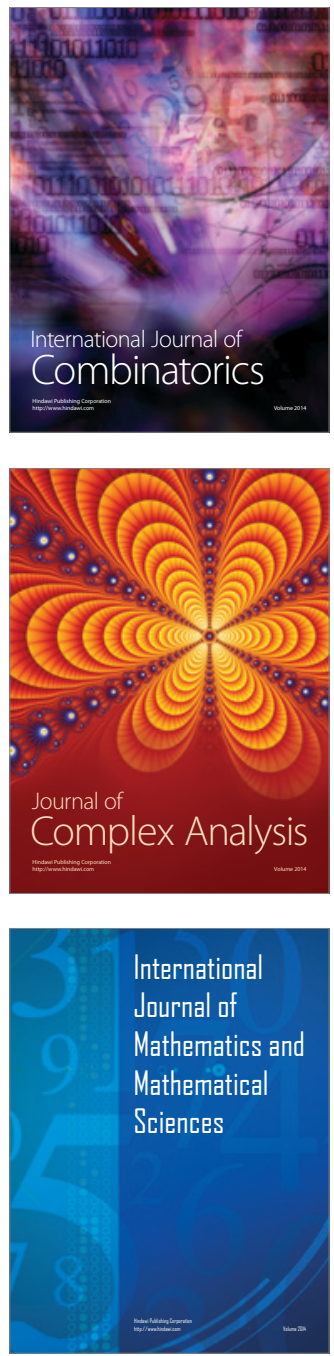
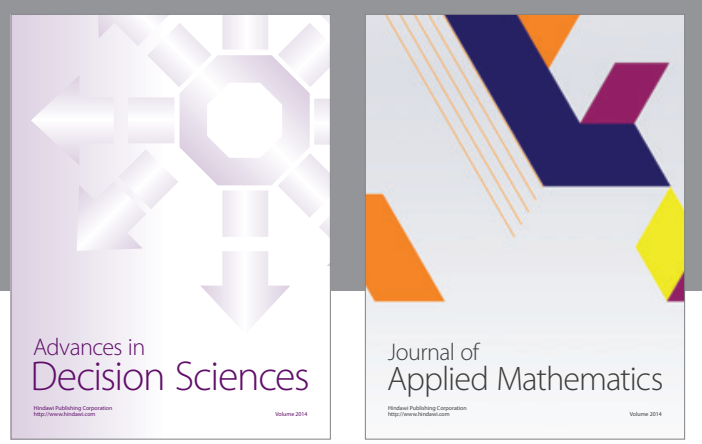

Algebra

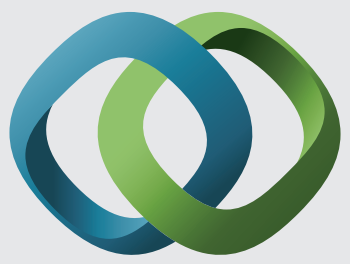

\section{Hindawi}

Submit your manuscripts at

http://www.hindawi.com
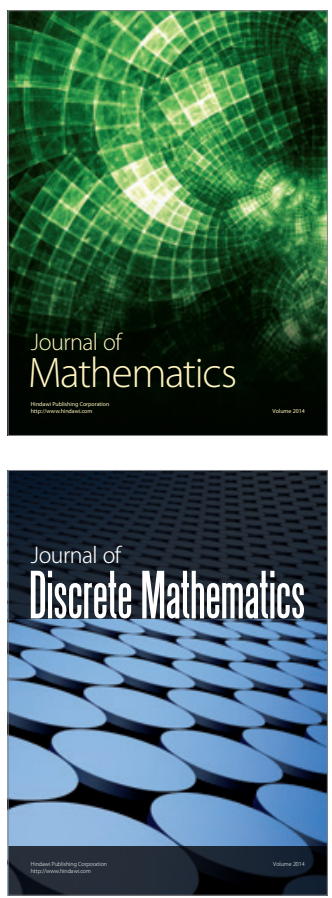

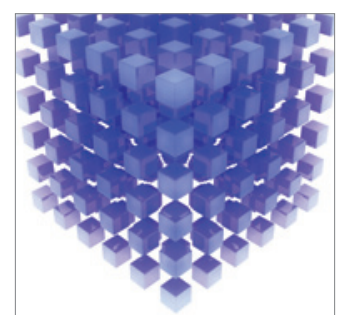

Mathematical Problems in Engineering
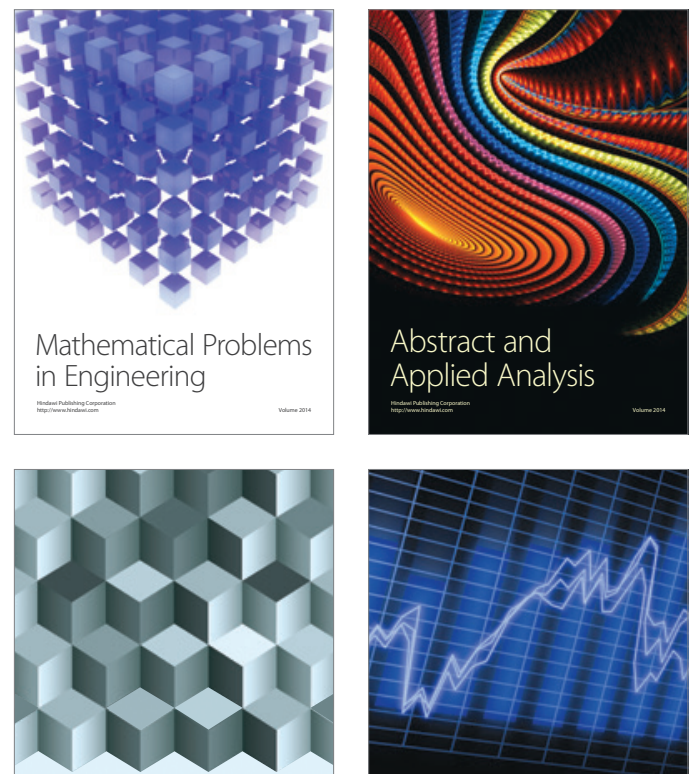

Journal of

Function Spaces

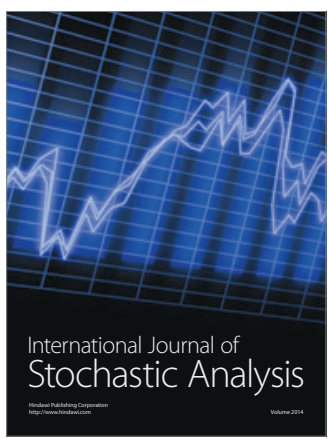

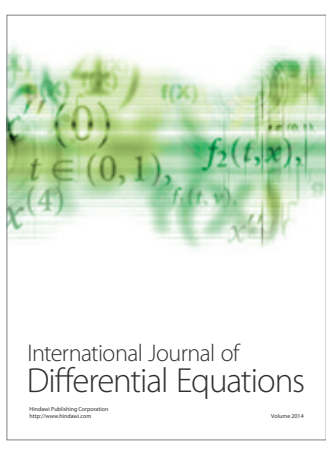
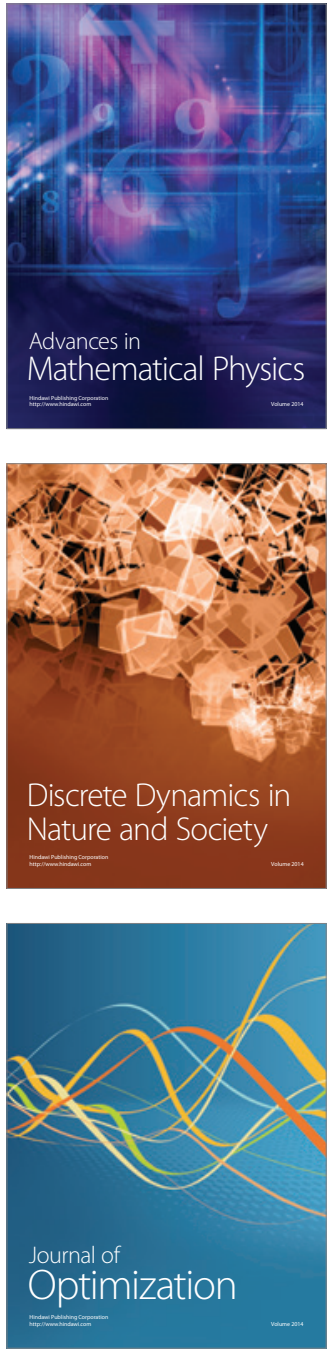